\title{
Optimaliseren geneesmiddelengebruik door ouderen
}

\begin{abstract}
Samenvatting
Kwint H-F, Faber A, Gussekloo J, Bouvy ML. Optimaliseren geneesmiddelengebruik door ouderen. Huisarts Wet 2015;58(3):134-8.

In het kader van het proefschrift Improving appropriate medication use for older people in primary care hebben we onderzoek verricht naar het optimaliseren van de kwaliteit van het geneesmiddelengebruik door ouderen met polyfarmacie in de eerste lijn, waarbij de focus lag op medicatiebeoordeling en medicatie op rol. In dit artikel beschrijven we enkele onderzoeken uit dit proefschrift. We bespreken het effect van medicatiebeoordeling op farmacotherapiegerelateerde problemen, ziektegerelateerde uitkomsten en de kwaliteit van leven. Daarnaast richten we ons meer specifiek op de verschillende stappen van het proces van medicatiebeoordeling, zoals de bijdrage van de farmacotherapeutische anamnese en het mogelijke aandeel van expliciete STOPP-START-criteria bij de identificatie van farmacotherapiegerelateerde problemen. Voor gebruikers van medicatie op rol hebben we de mate van ongewenste farmacotherapie onderzocht en hebben we hun therapietrouw en medicatiekennis vergeleken met die van gebruikers van reguliere verpakkingen. De onderzoeken in dit proefschrift tonen de bijdragen van verschillende stappen van het proces van medicatiebeoordeling bij ouderen en de uitkomsten van dit proces. Onderzoeken onder oudere gebruikers van medicatie op rol geven inzicht in de kwaliteit van het geneesmiddelgebruik van deze specifieke groep. Vervolgonderzoek is gewenst. Zo willen we bijvoorbeeld weten welke specifieke groep ouderen het meest baat heeft bij een medicatiebeoordeling of gebruik van medicatie op rol.
\end{abstract}

\section{INLEIDING}

$\mathrm{D}^{\mathrm{s}}$ implementatie van uiteenlopende behandelrichtlijnen bij ouderen met complexe problematiek heeft geleid tot een toename van het gebruik van geneesmiddelen. ${ }^{1-3}$ Inmiddels gebruiken meer dan 1 miljoen ouderen 5 of meer geneesmiddelen, wat we ook wel 'polyfarmacie' noemen. ${ }^{4}$ Door de vergrijzing zal dit aantal in de komende decennia verder toenemen. ${ }^{5}$ In 2006 liet het HARM-onderzoek zien dat 5,6\% van de ziekenhuisopnamen in Nederland geneesmiddelgerelateerd is en dat bijna de helft daarvan vermijdbaar was. ${ }^{6}$ Mede op grond van deze cijfers beveelt de Multidisciplinaire richtlijn Polyfarmacie bij ouderen tegenwoordig een jaarlijkse medicatiebeoordeling aan voor ouderen met polyfarmacie. Naast aandacht voor far-

SIR Institute for Pharmacy Practice and Policy, Theda Mansholtstraat 5-B, 2331 JE, Leiden: dr. H-F. Kwint, apotheker/onderzoeker; dr. A. Faber, apotheker/onderzoeker; M.L. Bouvy, hoogleraar farmaceutische patiëntenzorg. LUMC, afdeling Public Health en Eerstelijnsgeneeskunde, Leiden: prof.dr. J. Gussekloo, hoofd sectie Wetenschappelijk onderzoek Eerstelijnsgeneeskunde. Utrecht Institute for Pharmaceutical Sciences (UIPS), afdeling Farmaco-epidemiologie en Klinische Farmacologie, Utrecht: prof.dr. M.L. Bouvy, hoogleraar Farmaceutische patiëntenzorg • Correspondentie: h.f.kwint@apotheekstevenshof.nl•Mogelijke belangenverstrengeling: Henk-Frans Kwint heeft voor het uitvoeren van de verschillende onderzoeken in het proefschrift financiële ondersteuning ontvangen van Apotheek Voorzorg, KNMP, BENU Apotheken, Astra Zeneca, Achmea, Menzis en de coöperatie Connecting Care. macotherapiegerelateerde problemen (FTP's), zoals onder- en overbehandeling, niet-effectieve behandeling, (risico op) bijwerkingen en interacties, beveelt de richtlijn ook aan aandacht te besteden aan ordeningsproblemen. ${ }^{6,8} \mathrm{Er}$ is sprake van een ordeningsprobleem als de patiënt problemen ervaart bij het overzicht, beheer en inname van zijn geneesmiddelen..$^{8-10}$ Deze patiënten kunnen worden ondersteund door het verpakken van de geneesmiddelen in geïndividualiseerde distributievormen (GDV's) [figuur 1], zoals medicatie op rol ('Baxter').

Het proefschrift Improving appropriate medication use for older people in primary care bevat verschillende onderzoeken naar het optimaliseren van de kwaliteit van het geneesmiddelengebruik bij ouderen in de eerste lijn. ${ }^{14}$ Het gaat vooral in op effecten van medicatiebeoordeling, waarbij we een aantal onderzoeken hebben uitgevoerd onder ouderen die gebruikmaken van medicatie op rol.

\section{MEDICATIEBEOORDELING}

Medicatiebeoordeling beoogt de farmacotherapeutische behandeling van de patiënt te optimaliseren. Internationaal onderscheidt men verschillende vormen van beoordeling, die zijn gebaseerd op de gegevens die bij de beoordeling worden betrokken, zoals de medicatiegegevens, medische gegevens en een farmacotherapeutische anamnese bij de patiënt [figuur 2]. De optimale vorm van beoordeling is de zogenaamde clinical medication review, waarbij men al deze gegevens in de beoordeling meeweegt. Deze clinical medication review vormt ook het uitgangspunt voor de medicatiebeoordeling zoals dat is gedefinieerd binnen de in 2012 verschenen Multidisciplinaire richtlijn Polyfarmacie bij ouderen.7 Deze richtlijn onderscheidt vijf stappen binnen de medicatiebeoordeling:

- farmacotherapeutische anamnese;

- farmacotherapeutische analyse;

- overleg tussen de arts en de apotheker (opstellen van een farmacotherapeutisch behandelplan);

\section{De kern}

- Medicatiebeoordeling lost een aanzienlijk aantal farmacotherapiegerelateerde problemen op. Dit vertaalt zich echter in beperkte mate in meetbare klinische uitkomsten.

- De farmacotherapeutische anamnese en het gebruik van impliciete criteria als instrument binnen de farmacotherapeutische analyse zijn van belang om farmacotherapiegerelateerde problemen te identificeren.

- Een intensievere samenwerking tussen huisarts en apotheker bij de medicatiebeoordeling leidt tot een hogere implementatiegraad van aanbevelingen.

- Gebruikers van medicatie op rol rapporteren een hoge therapietrouw en een lage medicatiekennis. Bij deze gebruikers zien we relatief veel farmacotherapiegerelateerde problemen. 
- overleg tussen de arts en de patiënt (vaststellen van het behandelplan);

- follow-up en monitoring.

De eerste stap, de farmacotherapeutische anamnese, bestaat uit een gesprek met de patiënt over de ervaringen en problemen met zijn medicatie. In een dwarsdoorsnedeonderzoek onderzochten wij wat de bijdrage is van de farmacotherapeutische anamnese door de apotheker aan het totaal van geidentificeerde FTP's. ${ }^{11}$ Medicatiebeoordeling bij 155 patiënten leverde gemiddeld 1o FTP's per patiënt op. Zevenentwintig procent van deze FTP's bleek zijn oorsprong te hebben in de anamnese, de overige kwamen voort uit de analyse van medicatie- en medische gegevens. Vergeleken met FTP's afkomstig uit medicatie- en medische gegevens kenden apothekers aan FTP's die voortvloeiden uit anamneses vaker een hogere klinische relevantie toe, afgaande op de toegekende prioriteit en op het aantal medicatiewijzigingen na de medicatiebeoordeling. Hieruit blijkt dat bij een medicatiebeoordeling zonder een farmacotherapeutische anamnese een aanzienlijk deel van de klinisch relevante problemen zal worden gemist.

Over de tweede stap van de medicatiebeoordeling, de farmacotherapeutische analyse, adviseert de richtlijn voor het identificeren van FTP's impliciete en expliciete screeningsmethoden. De impliciete methode is een gestructureerde vragenlijst waarbij een deskundige systematisch beoordeelt welke geneesmiddelen geen indicatie (meer) hebben, voor welke indicatie medicatie ontbreekt, of de geneesmiddelen effectief en veilig zijn in het gebruik en of er sprake is van gebruiksproblemen. Een voorbeeld van een impliciete methode is de STRIP-methode (Systematic Tool to Reduce Inappropriate Prescribing), die wordt beschreven in de multidisciplinaire richtlijn Polyfarmacie bij ouderen. ${ }^{7}$ Om impliciete screeningsmethoden goed te kunnen gebruiken moet de deskundige over uitgebreide klinische en farmacologische kennis beschikken. ${ }^{12}$ Expliciete screeningsmethoden bestaan uit lijsten van voor ouderen minder geschikte geneesmiddelen en van geneesmiddelen die niet mogen ontbreken bij een bepaalde aandoening, bijvoorbeeld cholesterolverlagers bij diabetes. Deze expliciete criteria zijn doorgaans gemakkelijker in het gebruik en zijn tevens geschikt als checklist binnen een impliciete methode. ${ }^{12}$ Een voorbeeld van expliciete criteria zijn de STOPP-START-criteria [kader]. ${ }^{13}$ Ook expliciete criteria zijn niet altijd van toepassing op iedere individuele patiënt en daarom kan beargumenteerd afwijken wenselijk zijn. ${ }^{7}$

Er is nog niet eerder onderzocht in welke mate FTP's die men door middel van een impliciete screeningsmethode heeft opgespoord ook gevonden hadden kunnen worden met behulp van expliciete STOPP-START-criteria. ${ }^{14}$ Ons onderzoek laat zien dat het bij $82 \%$ van door impliciete criteria geïdentificeerde FTP's niet om STOPP-START-criteria ging. Het percentage aanwezige START-criteria was hoger dan het percentage STOPP-criteria (13\% versus 5,7\%; $\mathrm{p}<0$,o1). STOPP-criteria bleek men echter vaker te implementeren dan START-criteria (56\% versus 39\%; $\mathrm{p}<0,01$ ). We concluderen dan ook dat expliciete criteria zoals STOPP-
Figuur 1 Farmacotherapeutische interventies voor ouderen met polyfarmacie

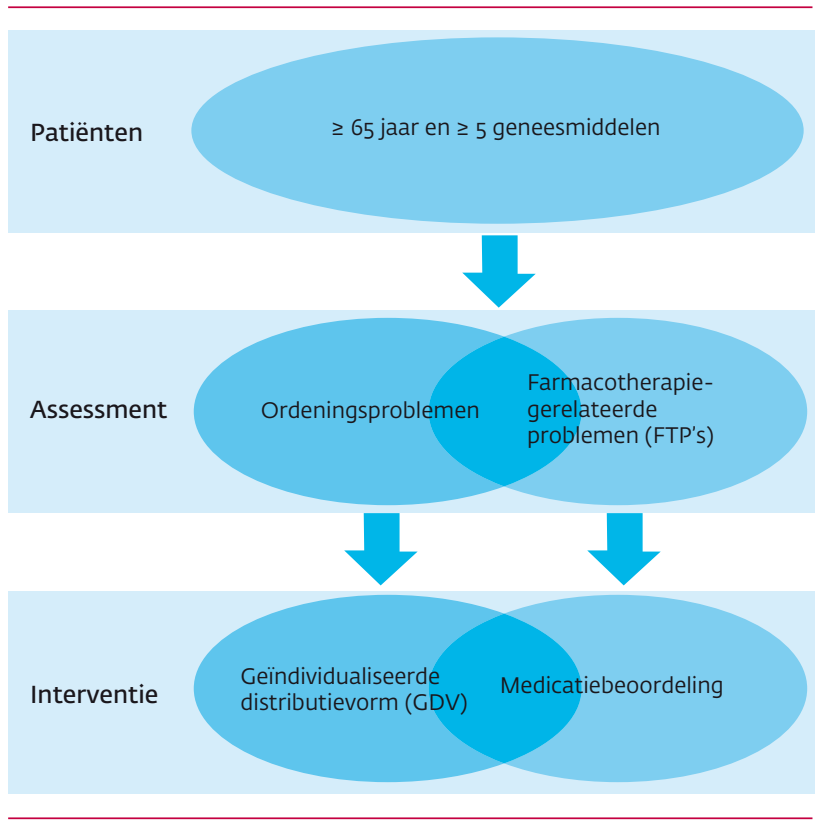

START een beperkte rol hebben bij de medicatiebeoordeling in de eerste lijn en dat een impliciete screeningsmethode het belangrijkste instrument is voor het opsporen van FTP's.

Bij de derde stap van de medicatiebeoordeling stellen huisarts en apotheker in onderling overleg een farmacotherapeutisch behandelplan op. In het proefschrift hebben we een systematisch literatuuronderzoek opgenomen naar de relatie tussen de samenwerking van huisarts en apotheker tijdens de medicatiebeoordeling en de implementatiegraad van uit-

\section{Abstract}

Kwint H-F, Faber A, Gussekloo J, Bouvy ML. Optimizing medication use for elderly patients. Huisarts Wet 2015;58(3):134-8.

The thesis Improving appropriate medication use for older people in primary care investigated how the medication use of elderly patients on polypharmacy in primary care can be optimized, with emphasis on the effects of medication review and multidose dispensing systems. In this article, we present a series of studies from this thesis. We describe the effect of medication review on drug-related problems, disease-specific outcomes, and health-related quality of life. Thereafter we focus on the different steps of the medication review process, such as the medication history and the possible role of explicit STOPP-START criteria in the identification of drug-related problems. We investigated the extent of inappropriate prescribing to older patients receiving their drugs via multidose drug dispensers and compared the self-reported medication adherence and knowledge of these patients with those of patients receiving manually dispensed drugs.

In conclusion, the studies presented in the thesis show the importance of the different steps of the medication review process when prescribing for elderly patients and the outcomes achieved. Studies of older users of multidose drug dispensing systems provide insight into the quality of medication use in these individuals. Further research is needed, for example, to determine which older patients will benefit the most from medication review or use of multidose drug dispensing systems. 
Figuur 2 Verschillende typen medicatiebeoordeling in de internationale literatuur, gebaseerd op beschikbaarheid van gegevens $\mathbf{5}^{7,11,12}$

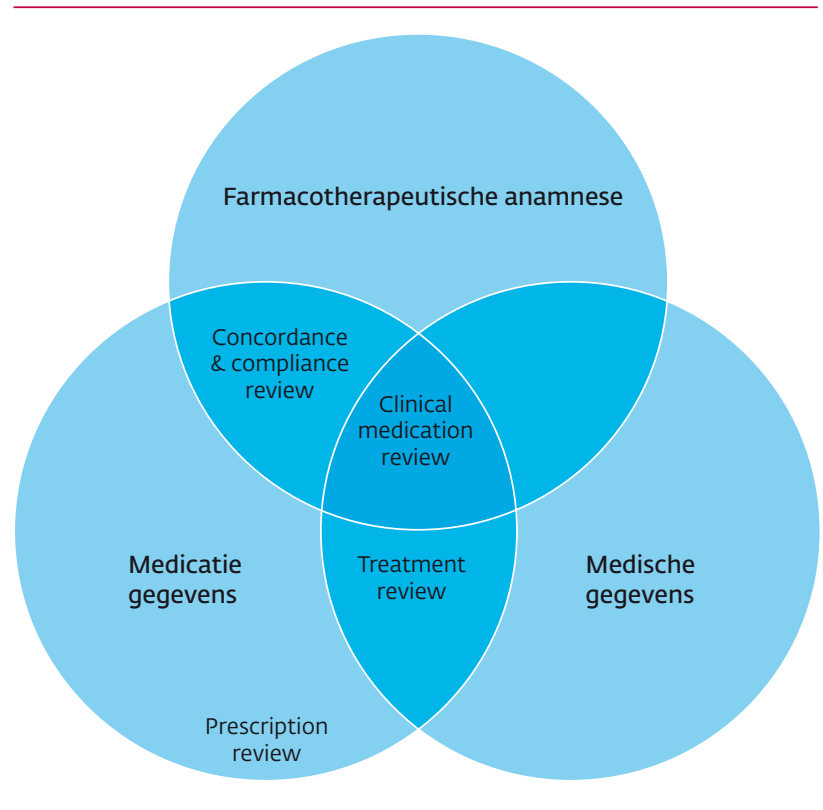

komsten van medicatiebeoordeling. ${ }^{15}$ Uiteindelijk hebben we twaalf onderzoeken op het gebied van medicatiebeoordeling geanalyseerd. We scoorden de aanwezigheid van de volgende acht kernelementen van samenwerking: klinische ervaring van de apotheker, betrokkenheid van de eigen apotheker van de patiënt, de beschikbaarheid van medische gegevens voor de apotheker, een gesprek tussen de apotheker en de patiënt, het uitnodigen van patiënten door de huisarts, een face-to-faceoverleg tussen huisarts en apotheker, het opstellen van een behandelplan en het uitvoeren van een follow-up. Wij vonden een positieve relatie tussen het aantal elementen dat samenwerking weerspiegelt en de implementatiegraad van de aanbevelingen. Een intensievere samenwerking tussen huisarts en apotheker bij de medicatiebeoordeling lijkt zich te vertalen in een hogere implementatiegraad van de aanbevelingen.

Ten slotte beschrijven we in het proefschrift een gerandomiseerd gecontroleerd onderzoek bij 285 thuiswonende ouderen die minimaal vijf geneesmiddelen gebruiken, waarvan minimaal één voor hart- en vaatziekten of diabetes. We bestudeerden verschillende uitkomsten van medicatiebeoordeling, zoals FTP's, ziektegerelateerde uitkomsten (systolische bloeddruk, LDL-cholesterol en geglycosyleerd hemoglobine (HbA1c)) en de kwaliteit van leven (EQ-5D/VAS). ${ }^{14}$ De medicatiebeoordeling in dit onderzoek was gebaseerd op het Australische Home Medicines Review, waarbij de apotheker de farmacotherapeu-

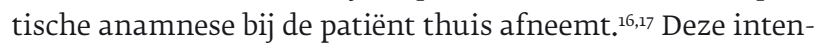
sieve vorm van medicatiebeoordeling loste een aanzienlijk deel van de FTP's op (30\%, 1,8 per patiënt) en verbeterde het LDL-cholesterol, maar gaf geen verbetering van andere ziektegerelateerde uitkomsten en de gezondheidsgerelateerde kwaliteit van leven na zes en twaalf maanden. Men bereikte dus geen verbeterde instelling op het gebied van hart- en vaatziekten en diabetes, wat ook deels te verklaren is uit het relatief lage percentage FTP's dat men voor deze aandoeningen heeft opgelost. De laatste jaren wordt het steeds duidelijker dat behandeling op basis van ziektegerelateerde uitkomsten bij ouderen, zoals beschreven in algemene cardiovasculaire en diabetesrichtlijnen, niet voldoet. Sterker nog, vooral bij kwetsbare ouderen zal de farmacotherapeutische behandeling zich meer moeten richten op patiëntspecifieke behandelvoorkeuren die zijn gerelateerd aan de kwaliteit van leven en wensen over onafhankelijkheid en levensduur. ${ }^{18,19}$

\section{GEÏNDIVIDUALISEERDE DISTRIBUTIEVORMEN}

Voor het ondersteunen van het medicatiebeheer bij ouderen bestaan diverse mogelijkheden. Zo kan de arts een toedieningsschema verstrekken en/of de patiënt kan zijn/haar geneesmiddelen zelf uitzetten in een weekcassette. Ook kan de apotheek ondersteuning bieden door middel van een herhaalservice, waarbij de apotheek na overleg met de huisarts de chronisch gebruikte geneesmiddelen per drie maanden klaarzet voor de patiënt. Indien de patiënt ondanks deze ondersteuning ordeningsproblemen ervaart, bijvoorbeeld door de complexiteit van toedieningsschema's of door praktische problemen bij het openen van verpakkingen of halveren van tabletten, kunnen de patiënt en de huisarts in overleg besluiten de geneesmiddelen te verstrekken in een geïndividualiseerde distributievorm (GDV) [figuur 1].$^{8-10}$. Hierbij moet men wel uitsluiten dat de patiënt geneesmiddelen bewust niet gebruikt. In dat geval heeft een GDV immers geen zin.

Een GDV is een specifieke distributie- en verpakkingsvorm waarbij de geneesmiddelen per dag en in de regel per tijdstip van inname geordend zijn in afzonderlijke compartimenten. ${ }^{10}$ De bekendste en meestgebruikte GDV in Nederland is de medicatie op rol ('Baxter'), waarbij de geneesmiddelen door een robot in plastic zakjes worden gedaan, die op een rol worden aangeleverd..$^{20-22} \mathrm{Er}$ is een sterke groei van het aantal GDV-gebruikers: in 2012 maakten 430.000 mensen hiervan gebruik, een stij-

\section{Kader STOPP-START-criteria}

In de jaren negentig van de vorige eeuw heeft men in Amerika een lijst van potentieel ongewenste geneesmiddelen ontwikkeld, de zogenaamde Beers-criteria. ${ }^{15}$ Deze lijst was vooral op de Amerikaanse praktijk gericht en veel Beers-geneesmiddelen waren in Europa niet beschikbaar. In 2008 heeft men een nieuwe expliciete screeningslijst van lerse oorsprong gepubliceerd die binnen Europa snel terrein wint. ${ }^{13}$ Dit instrument bestaat uit twee lijsten, de 'Screening tool of older person's prescriptions (STOPP)-criteria' en de 'Screening tool to alert doctors to right treatment (START)-criteria'.16 De lijst met STOPP-criteria bevat geneesmiddelen die potentieel ongeschikt zijn, terwijl de START-criteria zich richten op potentiële omissies, ofwel onderbehandeling. Voor de Nederlandse praktijksituatie heeft men een vertaling van de STOPP- en STARTcriteria gemaakt, ${ }^{14}$ die is opgenomen in de multidisciplinaire richtlijn Polyfarmacie bij ouderen.7 Hierbij heeft men geneesmiddelen die niet in Nederland zijn geregistreerd geschrapt en zijn de criteria getoetst en aangepast aan de vigerende Nederlandse richtlijnen (waaronder andere de NHG-Standaarden). ${ }^{14}$ 
ging van met 21\% ten opzichte van 2011. ${ }^{23}$ Vooral ouderen met polyfarmacie en patiënten met complexe psychiatrische problematiek maken gebruik van GDV. Vanwege de extra kosten die met de verstrekking van de medicatie op rol gepaard gaan hebben zorgverzekeraars hier voorwaarden voor opgesteld.

GDV's kunnen ordeningsproblemen verhelpen en zouden daarmee de therapietrouw kunnen verbeteren. ${ }^{10,20,24}$ Vooralsnog waren er echter geen onderzoeksgegevens die deze veronderstelling ondersteunen. ${ }^{22,25}$ Daarnaast was het de vraag of de patiënt (nog) op de hoogte is van de indicatie van de geneesmiddelen als deze uit de oorspronkelijke verpakking zijn verwijderd. ${ }^{26}$ Daarom vergeleken we de zelfgerapporteerde therapietrouw en medicatiekennis van 119 oudere gebruikers van medicatie op rol met die van 96 oudere gebruikers van reguliere verpakkingen van geneesmiddelen in zeven apotheken. ${ }^{27}$ Het percentage patiënten dat therapietrouw was voor alle geneesmiddelen was hoger voor de gebruikers van medicatie op rol $(81 \%)$ dan voor gebruikers van reguliere verpakkingen (58\%). Dit verschil was onafhankelijk van medicatiekennis en cognitief functioneren. Het percentage patiënten met adequate medicatiekennis was daarentegen juist lager onder gebruikers van medicatie op rol $(40 \%)$ dan voor gebruikers van reguliere verpakkingen $(79 \%)$. Een bijzondere bevinding was dat gebruikers van medicatie op rol ook meestal regulier verpakte geneesmiddelen gebruikten (bijvoorbeeld crèmes, inhalatoren of andere middelen die niet in de rol verpakt kunnen worden) en hiervoor wel een hoge medicatiekennis rapporteerden.

Er zijn zorgen dat geneesmiddelen in GDV's worden herhaald zonder dat de arts de noodzaak en effecten van de geneesmiddelen nog eens beoordeelt. ${ }^{28} \mathrm{Bij}$ een pragmatisch gerandomiseerd onderzoek in zes apotheken hebben we daarom een medicatiebeoordeling uitgevoerd bij 118 oudere gebruikers van medicatie op rol. ${ }^{20}$ We wezen patiënten at random toe aan een interventiegroep, waarbij direct een medicatiebeoordeling werd uitgevoerd, of de controlegroep, waarbij deze beoordeling pas aan het eind van het onderzoek plaatsvond. In beide groepen zagen we een groot aantal FTP's (gemiddeld 8,5 per patiënt). Bij ongeveer de helft van deze problemen kreeg de patiënt het advies voor een medicatiewijziging (gemiddeld 4,5 per patiënt). Na medicatiebeoordeling nam het aantal FTP's in de interventiegroep met $30 \%$ af ten opzichte van een spontane daling van $5 \%$ in de controlegroep. Op grond van deze bevinding kunnen we concluderen dat medicatiebeoordeling voor gebruikers van medicatie op rol aan te bevelen is.

\section{CONCLUSIES}

De beschreven onderzoeken maken duidelijk dat medicatiebeoordeling voor ouderen niet kan plaatsvinden zonder een farmacotherapeutische anamnese. Ook tonen ze aan dat toepassing van alleen expliciete criteria onvoldoende is voor een goede medicatiebeoordeling en dat gebruik van een impliciete screeningsmethode, zoals de STRIP-methode, door een deskundige noodzakelijk is. Uit literatuuronderzoek blijkt daarnaast dat een intensievere samenwerking tussen huisarts en apotheker leidt tot een effectievere medicatiebeoordeling.
Verder vormen de oudere gebruikers van 'medicatie op rol' een belangrijke doelgroep voor medicatiebeoordeling vanwege het hoge aantal farmacotherapiegerelateerde problemen dat we konden identificeren. Ten slotte toont ons onderzoek voor het eerst aan dat deze oudere gebruikers van medicatie op rol een hogere therapietrouw en tegelijkertijd een lage medicatiekennis rapporteren, vergeleken met gebruikers van reguliere verpakkingen.

\section{TOEKOMST}

Onze verschillende onderzoeken naar medicatiebeoordeling laten een grote variatie zien in de aantallen farmacotherapiegerelateerde problemen per patiënt, wat suggereert dat niet elke oudere patiënt een uitgebreide medicatiebeoordeling behoeft. De multidisciplinaire richtlijn noemt een aantal risicofactoren voor ouderen met polyfarmacie (bijvoorbeeld verminderde cognitie, verminderde nierfunctie, therapieontrouw) op grond waarvan een medicatiebeoordeling geïndiceerd is. Het is de vraag of we aan de hand van deze risicofactoren de patiëntengroep met de meest klinisch relevante FTP's kunnen selecteren. Vervolgonderzoek naar risicofactoren die de aanwezigheid van farmacotherapiegerelateerde problemen voorspellen kan de doeltreffendheid van medicatiebeoordeling verbeteren [figuur 3]. Een beperkte anamnese bij de oudere over het voorkomen van bijwerkingen, ordeningsproblemen en problemen met de effectiviteit van het geneesmiddel zou een voorspellende waarde kunnen hebben voor de aanwezigheid van (klinisch relevante) farmacotherapiegerelateerde problemen. De apotheker kan ook met behulp van het apotheekinformatiesysteem vooraf patiënten selecteren op basis van het aantal verschillende geneesmiddelen en innamemomenten, dan wel een of meer potentieel ongewenste geneesmiddelen. Ten slotte verwachten we dat in het bijzonder zogenaamde kwetsbare ouderen met multimorbiditeit meer kunnen profiteren van een medicatiebeoordeling.

Ook het proces van medicatiebeoordeling lijkt voor verbetering vatbaar. In de praktijk betreft het vooral de implementatie van aanbevelingen en afgesproken acties van arts en apotheker. Daarom zou vervolgonderzoek zich ook moeten richten op de redenen waarom de apotheker aanbevelingen na het overleg met de arts bij stap 3 niet doorvoert en op het haperen van de implementatie en follow-up in de laatste twee stappen van het medicatiebeoordelingsproces.

Naast de juiste patiëntengroep en het proces van medicatiebeoordeling is ook de juiste uitkomstmaat voor medicatiebeoordeling van belang. Een medicatiebeoordeling die nog meer focust op de specifieke behoeften, zorgen en klachten van de patiënt heeft mogelijk meer effect op de kwaliteit van leven. Vervolgonderzoek zou zich kunnen richten op de behandelvoorkeuren van de patiënt, zoals vermindering van pijn en andere klachten, en wensen met betrekking tot levensduur en onafhankelijkheid. ${ }^{17,18}$

Ons onderzoek laat zien dat de therapietrouw onder gebruikers van medicatie op rol hoger lijkt dan bij gebruikers van 
Figuur 3 Potentiële gegevensbronnen voor medicatiegerelateerde risicofactoren van ouderen

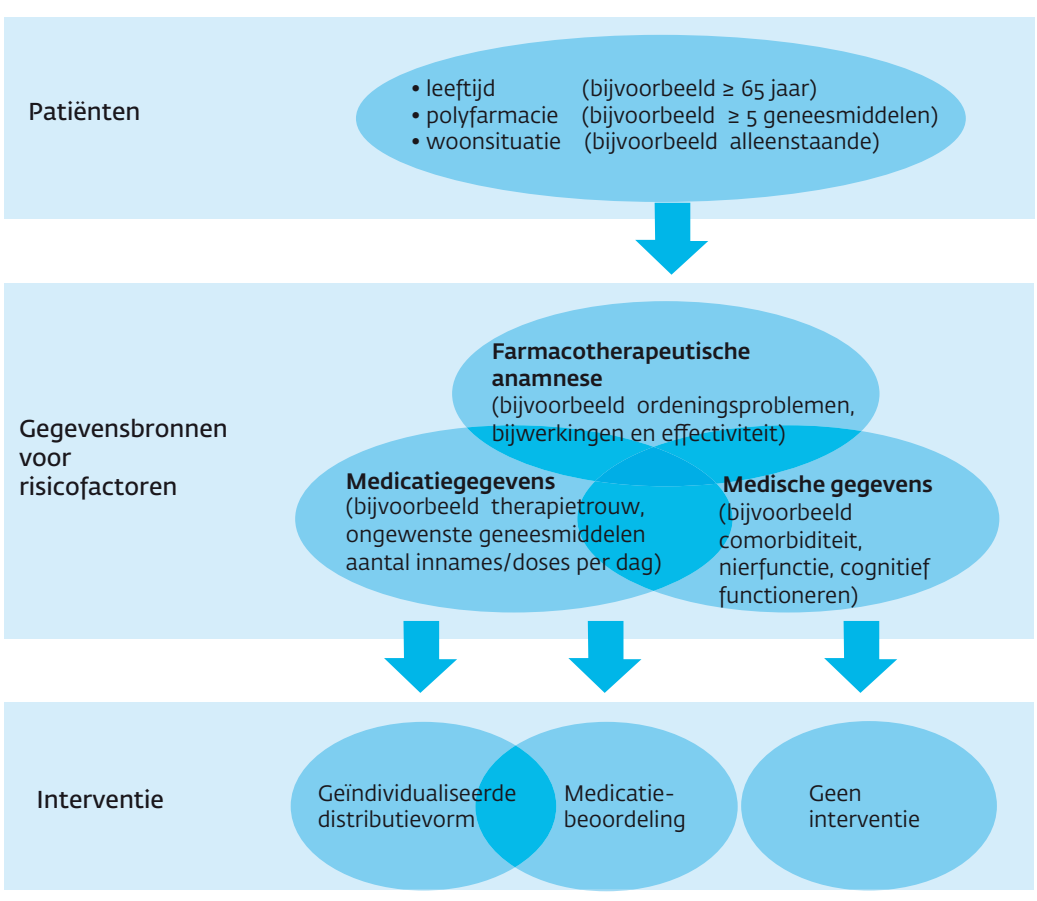

geneesmiddelen in reguliere verpakkingen, maar ook dat de kennis van geneesmiddelen in de eerste groep juist lager is, onafhankelijk van het cognitief functioneren. Het is de vraag of al deze gebruikers daadwerkelijk ordeningsproblemen hebben waarvoor medicatie op rol geïndiceerd zou zijn. Anderzijds zijn er vermoedelijk ook (oudere) patiënten die niet gebruikmaken van medicatie op rol of een andere GDV, maar daar wel baat bij zouden kunnen hebben. Toekomstig onderzoek zou in kaart moeten brengen wat de achterliggende redenen zijn voor het gebruik van een GDV, en tegelijkertijd antwoord moeten geven op de vraag of gebruikers van reguliere verpakkingen ordeningsproblemen ervaren en of de GDV deze problemen oplost. Ten slotte liet ons onderzoek zien dat het aandeel van potentieel ongewenste farmacotherapie bij gebruikers van medicatie op rol aanzienlijk is. Vervolgonderzoek naar de vraag of een medicatiebeoordeling bij de start van een GDV, zoals medicatie op rol, het aandeel ongewenste farmacotherapie kan verminderen lijkt daarom aangewezen.

\section{LITERATUUR}

1 Hubbard RE, O'Mahony MS, Woodhouse KW. Medication prescribing in frail older people. Eur J Clin Pharmacol 2012;69:319-26.

2 Hajjar ER, Cafiero AC, Hanlon JT. Polypharmacy in elderly patients. Am J Geriatr Pharmacother 2007;5:345-51.

3 Gnjidic D, Hilmer SN, Blyth FM, Naganathan V, Cumming RG, Handelsman DJ, et al. High-risk prescribing and incidence of frailty among older community-dwelling men. Clin Pharmacol Ther 2012;91:521-8.

4 Stichting Farmaceutische Kengetallen. Polyfarmacie bij een op de tien apotheekbezoekers. Pharm Weekbl 2012;39:1000.
5 Cerreta F, Eichler HG, Rasi G. Drug policy for an aging population - the European Medicines Agency's geriatric medicines strategy. N Engl J Med 2012;367:1972-4

6 Leendertse AJ, Egberts AC, Stoker LJ, Van den Bemt PM. Frequency of and risk factors for preventable medication-related hospital admissions in the Netherlands. Arch Intern Med 2008;168:1890-6.

7 Verduijn MM, Leendertse AJ, Moeselaar A, De Wit N, Van Marum RJ. Multidisciplinaire richtlijn Polyfarmacie bij ouderen. Huisarts Wet 2013;55:160-5.

8 Granas AG, Bates I. Patients' understanding and management of their illnesses and prescribed medicines - a descriptive study. Pharm World Sci 2005;27:321-8.

9 Tordoff JM, Bagge ML, Gray AR, Campbell AJ, Norris PT. Medicine-taking practices in community-dwelling people aged $>$ or $=75$ years in New Zealand. Age Ageing 2010;39:574-80.

10 KNMP-richtlijn. Zorg voor patiënten met geneesmiddelen in een geïndividualiseerde distributievorm. Den Haag: Koninklijke Nederlandse Maatschappij ter bevordering der Pharmacie, 2013.

11 Kwint HF, Faber A, Gussekloo J, Bouvy ML. The contribution of patient in terviews to the identification of drug-related problems in home medication review. J Clin Pharm Ther 2012;37:674-80.

12 Vermeulen Windsant-van den Tweel AM, Verduijn MM, Derijks HJ, Van Marum RJ. Detectie van ongeschikt medicatiegebruik bij ouderen; worden de STOPP- en START-criteria de nieuwe standaard? Ned Tijdschr Geneeskd 2012;156:A5076.

13 Gallagher P, Ryan C, Byrne S, Kennedy J, O’Mahony D. STOPP (Screening Tool of Older Person's Prescriptions) and START (Screening Tool to Alert doctors to Right Treatment). Consensus validation. Int J Clin Pharmacol Ther 2008;46:72-83.

14 Kwint HF. Improving appropriate medication use by older people in primary care. Dissertation. Rotterdam: Optima, 2013.

15 Kwint HF, Bermingham L, Faber A, Gussekloo J, Bouvy ML. The Relationship between the extent of collaboration of general practitioners and pharmacists and the implementation of recommendations arising from medication review: a systematic review. Drugs Aging 2013;30:91-102.

16 Sorensen L, Stokes JA, Purdie DM, Woodward M, Elliott R, Roberts MS. Medication reviews in the community: results of a randomized, controlled effectiveness trial. Br J Clin Pharmacol 2004;58:648-64.

17 Sorensen L, Stokes JA, Purdie DM, Woodward M, Roberts MS. Medication management at home: medication-related risk factors associated with poor health outcomes. Age Ageing 2005;34:626-32.

18 Schuling J, Sytema R, Berendsen AJ. Aanpassen medicatie: voorkeur oudere patiënt telt mee. Ned Tijdschr Ceneeskd 2013;157:A6491.

19 Schuling J, Gebben H, Veehof LJ, Haaijer-Ruskamp FM. Deprescribing medication in very elderly patients with multimorbidity: the view of Dutch GPs. A qualitative study. BMC Fam Pract 2012;13:56.

20 Kwint HF, Faber A, Gussekloo J, Bouvy ML. Effects of medication review on drug-related problems in patients using automated drug-dispensing systems: a pragmatic randomized controlled study. Drugs Aging 2011;28:30514.

21 Wekre LJ, Spigset O, Sletvold O, Sund JK, Grimsmo A. Multidose drug dispensing and discrepancies between medication records. Qual Saf Health Care 2010;19:e42.

22 Johnell K, Fastbom J. Multi-dose drug dispensing and inappropriate drug use: a nationwide register-based study of over 700,000 elderly. Scand J Prim Health Care 2008;26:86-91.

23 College voor zorgverzekeringen (CVZ). GIPeilingen 2012. Ontwikkelingen genees- en hulpmiddelengebruik. http://www.cvz.nl/binaries/content/ documents/zinl-www/documenten/publicaties/gipeilingen/1310-gipeilingen-2012/GIPeilingen+2012.pdf.

24 Barat I, Andreasen F, Damsgaard EM. Drug therapy in the elderly: what doctors believe and patients actually do. Br J Clin Pharmacol 2001;51:61522.

25 Reuther LO, Lysen C, Faxholm M, Salomon L, Hendriksen C. Multi-dose drug dispensing is a challenge across the primary-secondary care interface. Dan Med Bull 2011;58:A4341.

26 Nunney J, Raynor DK, Knapp P, Closs SJ. How do the attitudes and beliefs of older people and healthcare professionals impact on the use of multi-compartment compliance aids? A qualitative study using grounded theory. Drugs Aging 2011;28:403-14.

27 Kwint HF, Stolk G, Faber A, Gussekloo J, Bouvy ML. Medication adherence and knowledge of older patients with and without multidose drug dis pensing. Age Ageing 2013;42:620-6.

28 Halvorsen KH, Granas AC, Engeland A, Ruths S. Prescribing quality for older people in Norwegian nursing homes and home nursing services using multidose dispensed drugs. Pharmacoepidemiol Drug Saf 2012;21:929-36 